ESTUDIOS

\title{
Análisis documental de la integración regional del derecho internacional de la seguridad social
}

Documentary analysis of the regional integration of international social security law

\author{
Gabriela Mendizábal Bermúdez \\ Universidad Autónoma del Estado de Morelos, México
}

\begin{abstract}
RESUMEN La globalización aumentó el traslado de mercancías, trabajadores y personas en general y sometió a los ciudadanos de un Estado a normas jurídicas de otro y a requerir de la protección de la seguridad social de un país en el que son extranjeros. El derecho ha acompañado este proceso mediante diversos instrumentos internacionales en los que se advierte una mayor regionalización. Es por ello que, con una revisión documental y método deductivo, se analiza la composición del derecho internacional de la seguridad social por continente, demostrando que la seguridad social es un derecho humano que la integración regional potencia a través de sus normas internacionales y de las resoluciones de sus órganos regionales de impartición de justicia.
\end{abstract}

PALABRAS CLAVE Derecho internacional de la seguridad social, integración regional, seguridad social, derechos humanos, globalización.

ABSTRACT Globalization has increased the movement of goods, workers and people in general, subjecting citizens of one State to the legal norms of another and requiring the protection of social security of a country for people who are foreigners. The law has accompanied this process through various international instruments, which show greater regionalization. For this reason, by means of a documentary review, an analysis of the composition of international social security law by continent is carried out, out demonstrating that social security is a human right that regional integration strengthens through its international norms and the resolutions of its regional judicial bodies.

KEYWORDS International social security law, regional integration, social security, human rights, globalization. 


\section{Introducción}

La globalización ha tenido muchas consecuencias. Por ejemplo, se agilizó el intercambio de información, se aumentó el traslado de mercancías y también hemos visto un aumento en los índices de migración. Particularmente, la migración laboral ocasiona que los ciudadanos de un Estado deban someterse a normas jurídicas de otro y a requerir de la protección de la seguridad social de un país, en el que son extranjeros.

El problema se presenta cuando se deben otorgar prestaciones de seguridad social a un trabajador cuyas normas nacionales no incluyen su protección en el extranjero o los regímenes de acogida establecen requisitos de difícil alcance para los extranjeros para acceder a las prestaciones, como las pensiones que requieren de años de aseguramiento y cotización. El problema se encrudece cuando los migrantes no tienen una oferta de trabajo y se mueven a otros países en busca de una mejor calidad de vida, sin tener siquiera una estancia legal; sin embargo, aun así, requieren del cobijo de la seguridad social. Las normas nacionales cada vez se hacen más sensibles a los derechos humanos y la responsabilidad que existe a pesar de tratarse de migrantes con estatus migratorio irregular. ${ }^{1}$

En ese sentido, el derecho ha acompañado este proceso a través de diversos instrumentos internacionales como acuerdos, tratados, cartas de carácter internacional y convenios, dentro de los que se advierte una tendencia a la integración regional. Es decir, se establecen primero acuerdos comerciales que facilitan el intercambio de bienes y servicios e incluyen normativas para coordinar y cooperar en temas eminentemente económicos y comerciales. Esto lleva a una convergencia más profunda que extiende el alcance de la cooperación a temas políticos, sociales, culturales, ambientales y, por supuesto, laborales, lo que fomenta el traslado de trabajadores y la ampliación a la normativa de seguridad social. En el mejor de los casos, a través de la ratificación de los instrumentos internacionales se extiende la integración hasta la regulación de la libre circulación de personas y la garantía de sus derechos de seguridad social.

El primer y más importante ejemplo de esa integración regional es la Unión Europea, pero se advierte un aumento de la integración regional en cada una de las regiones continentales del planeta.

Es por ello, que dentro de este artículo se muestran los resultados de una investigación documental realizada aplicando los métodos deductivo y exegético, dividida en tres grandes apartados: el primero analiza la composición del derecho internacional de la seguridad social en un mundo global y lo que significa la integración

1. Al respecto se puede señalar como ejemplo la Ley de Migración mexicana vigente que ya hace una diferenciación y establece derechos para los migrantes en situación migratoria irregular. Ver Ley de Migración mexicana, artículo 3 (xxxiii), 2021, disponible en https://bit.ly/3CYXIYx. 
regional; para posteriormente, en un segundo apartado, analizarlo por continente, para demostrar que la integración regional contribuye a la concreción del derecho humano a la seguridad social a través de sus normas internacionales regionales y de las resoluciones de sus órganos regionales de impartición de justicia. Por último, el artículo cierra con un apartado de reflexiones a manera de conclusión y las respectivas fuentes de investigación.

\section{El derecho internacional de la seguridad social en un mundo global}

La seguridad social es un derecho humano establecido en diversos instrumentos internacionales y legislaciones nacionales, por lo que su reconocimiento no depende de fronteras (Mendizábal y Apáez, 2020: 244), además ha sido analizada por muchos especialistas. Con el paso de los años, el concepto dinámico de seguridad social se ha adaptado a los cambios sociales, culturales y jurídicos que se han suscitado, de manera internacional y local.

En ese sentido, uno de los instrumentos internacionales más importante que la reconocen como un derecho es la Declaración Universal de los Derechos Humanos de 1948, cuyo artículo 22 señala:

Toda persona, como miembro de la sociedad, tiene derecho a la seguridad social, y a obtener, mediante el esfuerzo nacional y la cooperación internacional, habida cuenta de la organización y los recursos de cada Estado, la satisfacción de los derechos económicos, sociales y culturales, indispensables a su dignidad y al libre desarrollo de su personalidad. ${ }^{2}$

Por su parte, el Pacto Internacional de Derechos Económicos, Sociales y Culturales (1976), enmarca en su artículo 9 que el derecho a la seguridad social se refiere a:

El derecho a gozar de la red de servicios de seguridad social en casos de enfermedad paternidad, viudez, desempleo, invalidez, etcétera, y al mecanismo que hace posible el sostenimiento del sistema, el abono continuo de los patrones sobre una parte del salario de los trabajadores para que accedan a esas prestaciones. ${ }^{3}$

Ahora bien, el Protocolo de San Salvador establece también en su artículo 9:

1) Toda persona tiene derecho a la seguridad social que la proteja contra las consecuencias de la vejez y de la incapacidad que la imposibilite física o mentalmente para obtener los medios para llevar una vida digna y decorosa. En caso de muerte del

2. Para más información véase «Declaración Universal de los Derechos Humanos», Organización de Naciones Unidas, 1948, disponible en https://n9.cl/imy5.

3. Para más información véase «Pacto internacional de derechos económicos, sociales y culturales», Organización de Naciones Unidas, 1976, disponible en https://bit.ly/3EYiedi. 
beneficiario, las prestaciones de seguridad social serán aplicadas a sus dependientes. 2) Cuando se trate de personas que se encuentran trabajando, el derecho a la seguridad social cubrirá al menos la atención médica y el subsidio o jubilación en casos de accidentes de trabajo o de enfermedad profesional y, cuando se trate de mujeres, licencia retribuida por maternidad antes y después del parto. ${ }^{4}$

No obstante, podemos señalar que hoy en día la seguridad social no solo es una aspiración, es un derecho humano que se positiviza en las normas constitucionales y también en normas internacionales y se materializa con los beneficios o prestaciones que de forma organizada el Estado garantiza a todos los individuos de la sociedad, a través de sistemas de seguros que se activan ante la actualización de riesgos o situaciones específicas (como enfermedad, vejez o maternidad), y que permiten satisfacer sus necesidades básicas (González y Maldonado, 2021:1).

Por tanto, a efectos de conseguir su objetivo primordial, la seguridad social debe ser dinámica. Solo por medio del cambio y la innovación la seguridad social puede responder proactivamente a los desafíos de la globalización y contribuir a la justicia social y a un desarrollo económico más igualitario (Konkolewsky, 2007).

\section{Conceptualización del derecho internacional de la seguridad social}

Montoya Melgar (1964: 399) señaló que el derecho internacional es un sistema de normas jurídicas que disciplina la realidad social internacional.

Puesto que una parte de esta realidad social se encuentra formada por las relaciones de las personas migrantes en territorios extranjeros y sus derechos de seguridad social, podemos decir en seguimiento al citado autor, que el derecho internacional de la seguridad social regula relaciones de seguridad social en el ámbito internacional.

Ulrich Becker (2012) señala que el derecho internacional de la seguridad social se puede entender de dos formas: por un lado, como la legislación social emitida por los Estados para regular los asuntos transfronterizos; 5 por otro lado, como las regulaciones emitidas por organizaciones internacionales en el campo del derecho de la seguridad social, es decir, organizaciones regionales y globales (Mendizábal, 2020: xv).

$\mathrm{Y}$ aunque se trata de una disciplina relativamente joven, se puede conceptualizar en atención a sus ámbitos de aplicación —objetivo y subjetivo, fuentes, naturaleza

4. Para más información véase «Protocolo de San Salvador», Organización de los Estados Americanos, disponible en https://bit.ly/30eOo6R.

5. La riqueza del lenguaje en español permite distinguir entre el derecho de la seguridad social internacional que corresponde a lo que el Becker (2012) menciona como la legislación social emitida por los Estados para regular los asuntos transfronterizos, en el entendido de que siguen siendo normas nacionales que regulan asuntos transfronterizos, y el DISS que corresponde a las regulaciones emitidas por organizaciones internacionales en el campo del derecho de la seguridad social, es decir, organizaciones regionales y globales; sin embargo, en alemán ambos son Internationale Sozialrecht. 
y aplicación de su normas-, como el conjunto de normas jurídicas que regulan las relaciones entre diversos sujetos de derecho internacional, con la finalidad de estandarizar, armonizar o coordinar la protección de seguridad social que brindan los Estados soberanos tanto a sus ciudadanos como a los inmigrantes, para apoyar a la política de desarrollo internacional socialmente justo (Mendizábal, 2020: xxiv).

Vistas desde un sentido amplio, las fuentes del derecho internacional de la seguridad social están integradas por los instrumentos internacionales en materia de seguridad social y la doctrina y la jurisprudencia que emiten las cortes internacionales de cada uno de los continentes, así como los principios generales del derecho.

En específico, las fuentes formales del derecho internacional de la seguridad social son aquellas que derivan de un proceso de creación de normas jurídicas (Cárdenas, 2009: 155) y se pueden clasificar en dos:

- Instrumentos jurídicos internacionales en materia de seguridad social que tienen como finalidad establecer una homologación en las prestaciones que se otorgan en determinados países o regiones de un continente; los que se pueden ver reflejados en tratados internacionales bilaterales, convenios multilaterales entre más de dos Estados y acuerdos de colaboración. Estos instrumentos serán vinculantes para cada uno de los Estados que hayan signado los compromisos contenidos dentro de los mismos.

- Marcos normativos que tengan como finalidad una coordinación o armonización de derechos y obligaciones en materia de seguridad social entre sistemas de distintos países, cuyo objetivo es proteger a las personas que generen derechos en la materia en dos o más Estados. Un claro ejemplo es la coordinación que existe entre los sistemas de seguridad social de los países de la Unión Europea gracias al Reglamento 883/2004 sobre la coordinación de los sistemas de seguridad social.

La existencia de instrumentos jurídicos internacionales en materia de seguridad social duros o de tipo vinculante garantiza con mayor efectividad el derecho a la seguridad social, pues al ser vinculantes entre las partes signadas se adquiere un mayor compromiso para el cumplimiento y aplicación en beneficio de sus sociedades. Asimismo, estos instrumentos internacionales dan pauta para que exista una evolución del derecho internacional de la seguridad social que atienda a las nuevas realidades que se viven en cada país.

\section{Integración regional y globalización}

Sin intentar hacer un estudio desde la economía o teoría económica sobre la integración regional, se pueden señalar algunas ideas básicas para su comprensión desde la perspectiva del derecho internacional de la seguridad social. 
A mediados del siglo XIX, como consecuencia de las guerras mundiales y las crecientes relaciones entre las naciones, surge la necesidad de la cooperación internacional. En tal virtud, se crean órganos internacionales en todas las temáticas posibles, concebidos para asegurar esa cooperación internacional. ${ }^{6}$

Organismos internacionales como la Organización de las Naciones Unidas (ONU), la Organización Internacional del Trabajo (OIT), la Organización Internacional para las Migraciones (OIM), entre otros, han coadyuvado en la integración de marcos jurídicos referenciales para establecer acuerdos y, en su caso, una homologación sobre puntos específicos.

La historia nos enseña que tanto el surgimiento de los organismos internacionales, como la base de la integración regional tienen un origen de carácter funcional, aunque con su desarrollo se marcan en cada región procesos de construcción de intereses distintos a los que les dieron origen.

La Cepal (2014) señala que la integración regional es un proceso multidimensional cuyas expresiones incluyen iniciativas de coordinación, cooperación, convergencia e integración profunda, y cuyo alcance abarca no solo las temáticas económicas y comerciales, sino también las políticas, sociales, culturales y ambientales, y, por supuesto, aquellas sobre aspectos normativos. Como lo refiere Pampillo (2019: 125) la importancia de la integración jurídica deriva en primer lugar de la trascendencia de los procesos de globalización, que han propiciado la conformación de bloques regionales.

La integración regional permite establecer lazos de cooperación más estrechos entre países con afinidad geográfica y que además tienen cierta similitud respecto a la economía, cultura, sociedad, política, sistemas normativos e incluso las problemáticas que se suscitan en sus territorios.

Estas similitudes permiten que exista una mayor coordinación en la aplicación de compromisos regionales, que se materializa a través de la suscripción de convenios o tratados, pues al ser parte de una determinada región geográfica la problemática o materia de la cooperación les es común y, por ende, el cumplimiento de los compromisos puede ser mayormente efectivo.

El economista húngaro Bela Balassa (Malamud, 2011: 220) señala que existen cuatro etapas de la integración regional: la primera es la zona de libre comercio entre los países que suscriben el acuerdo. La segunda etapa es la unión aduanera que ya forma una entidad económica internacional, cuyos integrantes son los países miembros del acuerdo y se caracteriza por establecer un arancel que se pagará por los productos provenientes de terceros países. La tercera etapa es el mercado común, caracterizado por la libre circulación de bienes y servicios, por lo que en materia de derecho de la

6. Por ejemplo, la Unión Postal General creada por el Congreso de Berna de 1874, la Unión Telegráfica Internacional formada en 1885 y la Organización Meteorológica Internacional constituida en 1878. 
seguridad social es sumamente importante, pues es en esta etapa en la que se fijan las bases y normas del derecho internacional de la seguridad social regional aplicables a los trabajadores y sus familias provenientes de los países miembros, para estar protegidos en el país receptor laboral. Eso implica la estandarización, armonización o coordinación de los marcos normativos nacionales, como presupuesto indispensable para establecer este tipo de cooperación. Por último, la cuarta etapa llega a la unión económica, que implica una armonización total entre los países signantes del acuerdo internacional. Balassa (1965: 16) señaló que «los países que se encuentran en una etapa superior de desarrollo fueron los que comenzaron a reflexionar en la necesidad de la integración, en tanto que las economías más atrasadas se han mantenido a la zaga». Esto se ha demostrado con la experiencia de la Unión Europea. A medida que el proceso avanza, se requiere unidad monetaria y mercado común y la ampliación de la cooperación del terreno económico, al político, laboral, cultural, ambiental, etcétera.

Dentro de esta etapa se expiden las normas del derecho internacional de la seguridad social aplicables a los Estados parte para protección de todas las personas como sujetos de un derecho humano y no ligados a una relación laboral; de tal forma, que llegar a la cuarta etapa puede compararse con una unificación estatal voluntaria.

Ahora bien, el fenómeno de la globalización no es antagónico a la regionalización. Si bien el desarrollo histórico de la internacionalización inicia con la regionalización, como parte de un proceso lógico de la cooperación internacional sin necesidad de la tecnología y empujado por las necesidades funcionales, continuó con el surgimiento de la internacionalización mediante organismos internacionales mundiales y el desarrollo de relaciones internacionales comerciales a escala global y podríamos augurar que se fortalece nuevamente la integración regional como parte de la globalización, evidenciando las necesidades y acciones locales no limitadas al aspecto económico.

En ese sentido, la globalización se puede entender como el proceso por el cual las economías del mundo se integran de forma creciente, en particular a través del comercio y los flujos financieros, pero también a través de movimientos de personas, conocimientos e ideas (Fanjul, 2021).

Ciertamente la globalización en un principio tenía como objetivo principal aspectos netamente económicos; sin embargo, este fenómeno ha evolucionado rápidamente gracias al desarrollo tecnológico y ha diversificado múltiples aspectos, como intercambios culturales, de personas y por supuesto la generación de marcos normativos comunes a través de convenios o tratados que versen sobre algún tema en específico.

De tal suerte, la globalización ha coadyuvado para establecer normas comunes entre muchos países que permiten la regulación de una forma homologada o coordinada entre las partes sobre una materia. Ejemplo de ello es la existencia de marcos normativos aplicables en materia de seguridad social como la iniciativa de la OIT de los pisos de protección social, que fomenta que los ciudadanos de diversos Estados 
puedan disfrutar del otorgamiento de los derechos que devienen del derecho humano a la seguridad social.

En ese sentido, la globalización ha permitido la celebración de instrumentos jurídicos de manera regional, continental o internacional con base en la organización de los Estados. En específico, se resalta la importancia de los instrumentos regionales aplicables a países de una región específica.

Las figuras de la globalización y la integración regional han contribuido a entablar instrumentos que son las fuentes del derecho internacional de la seguridad social: la globalización, expandiendo y abriendo las fronteras económicas, culturales, sociales y normativas para cambiar la forma en que los países se relacionan internacionalmente y la integración regional, permitiendo que determinados Estados con similitudes particulares puedan desarrollar normas aplicables sobre seguridad social que beneficie a las sociedades que pertenezcan a la región, pues es más conveniente negociar en bloque que de forma individual: de país a país.

Desde esa perspectiva, y en seguimiento a una tesis representativa central de la economía que señala que «el levantamiento de las restricciones al comercio y los movimientos de capital en todo el mundo aumenta el bienestar» ${ }^{7}$ (Felbermayr y otros, 2015), es que cobra mayor importancia analizar el desarrollo de la integración regional, desde su aspecto no económico, sino de seguridad social, principalmente a partir del derecho internacional de la seguridad social por región, coadyuvando al reconocimiento de la seguridad social como derecho humano, por lo que en los siguientes apartados se analiza el derecho internacional de la seguridad social por continente, incluyendo como elementos para el análisis: los aspectos generales de la zona geográfica, organismos internacionales, instrumentos internacionales y organismos de protección a derechos humanos, en específico el derecho humano a la seguridad social.

\section{Derecho internacional de la seguridad social en América Latina}

Aspectos generales de la zona geográfica en relación con la seguridad social

El continente americano presenta grandes asimetrías entre el norte y el sur, que se reconocen también en materia de seguridad social.

A los países del sur les une sus antecedentes históricos y sus consecuencias en la actualidad que repercuten en los sistemas de seguridad social.

Respecto a los países del norte, Estados Unidos y Canadá, su principal similitud recae en el idioma, así como los contextos económicos similares, en comparación con el resto de los países del continente americano, por lo que son los países preferidos

7. Traducción personal: «Die Aufhebung von Beschränkungen im Handel und Kapitalverkehr weltweit vermehrt die Wohlfahrt». 
por los latinoamericanos para migrar, con la finalidad de conseguir una mejor calidad de vida.

Dentro de América Latina encontramos organismos regionales conformados por diversos países, con el objetivo de coordinar, cooperar y, finalmente, integrarse en temas variados, que van desde el económico y comercial, hasta laborales, sociales, culturales y ambientales. Se pueden mencionar los siguientes: Mercado Común del Sur (Mercosur), Comunidad Andina (CAN), Comunidad del Caribe (Caricom), Unión de Naciones Suramericanas (Unasur), Sistema de la Integración Centroamericana (SICA), Alianza Bolivariana para los Pueblos de Nuestra América (ALBA), la Alianza del Pacífico y la Comunidad de Estados Latinoamericanos y Caribeños (Celac).

En tanto, en América del Norte solo se destaca la integración del nuevo acuerdo comercial Tratado entre México, Estados Unidos y Canadá (T-MEC) - anteriormente denominado Tratado de Libre Comercio de América del Norte entre México, Estados Unidos de América y Canadá- que establece una libre circulación de mercancías entre dichos países y pese a que se esperaba que fuera el instrumento base que diera pauta para la libre circulación de las personas, la cuestión no se prevé ni a largo plazo.

\section{Organismos regionales que expiden normas y directrices de seguridad social}

Dentro de esa asimetría norte-sur del continente americano, el derecho internacional de la seguridad social regional se compone por las directrices de los organismos regionales que tienen influencia directa en la seguridad social.

Los organismos internacionales regionales con injerencia en la seguridad social son:

- Conferencia Interamericana de Seguridad Social.

- Organización de los Estados Americanos. ${ }^{8}$

- Comunidad Andina.

- Comunidad del Caribe (Caricom).

- Sistema de Integración Centroamericana (SICA).

- Mercosur.

8. La Carta de la OEA reconoce principios, dentro de los que destacan dos con relación al DISS. El principio justicia señala «La justicia y la seguridad social son bases de una paz duradera», disponible en https://bit.ly/318bkDU. 


\section{Principales instrumentos internacionales} regionales en materia de seguridad social

Como fuente directa del derecho internacional de la seguridad social regional existen acuerdos y convenios, bilaterales y multilaterales vinculantes y no vinculantes, regionales con el objetivo de regular derechos de seguridad social entre los Estados signantes.

Por lo que respecta a los considerados como vinculantes sobresalen los siguientes:

- Convenio multilateral iberoamericano de seguridad social (CMISS).

- Convenio multilateral de Mercosur.

- Acuerdo de seguridad social de la comunidad del Caribe.

Por lo que respecta a instrumentos normativos no vinculantes se destacan dos: la Carta social de las Américas y la Declaración sociolaboral del Mercosur.

Como se puede observar, en América Latina existe una gran cantidad de instrumentos internacionales en materia de seguridad social que se pueden dividir en dos: aquellos cuya base son los derechos humanos - como la Carta de la OEA y la Carta social de las Américas- y otros que regulan relaciones de trabajo y seguridad social regionales, como el Convenio multilateral iberoamericano de seguridad social, el Convenio multilateral de Mercosur y el Acuerdo de seguridad social de la comunidad del Caribe.

Por lo que la base del derecho internacional de la seguridad social regional ha sido una negociación política para una integración económica y posteriormente se han establecido algunas normas en regiones latinoamericanas de seguridad social.

\section{Justicia regional: Del derecho humano a la seguridad social}

Por último, no puede faltar la escasa, pero sumamente importante, jurisprudencia generada a partir de las principales resoluciones de la Corte Interamericana de Derechos Humanos, que si bien no ha contribuido formalmente a la regionalización, sí contribuye de manera directa a la integración regional, ya que establecen una importante directriz para la aplicación del derecho humano a la seguridad social para el resto de las jurisdicciones nacionales que aceptan la autoridad de la Corte, estableciendo de alguna forma un derecho internacional de la seguridad social principalmente latinoamericano.

También se puede agregar que la postura de la Corte Interamericana de Derechos Humanos en relación con el derecho humano a la seguridad social ha evolucionado $\mathrm{y}$ es perceptible en los argumentos de algunas resoluciones: 
- El reconocimiento de la dimensión colectiva e individual de los derechos económicos, sociales y culturales. ${ }^{9}$

- El reconocimiento de un bloque de derechos humanos sin distinción de generaciones o características unificando a todos los derechos contenidos en la Convención Americana sobre Derechos Humanos. ${ }^{10}$

- La comprensión del principio de progresividad como una medida de tasación con base en el mismo Estado y no como una limitante de su exigibilidad inmediata. ${ }^{11}$

- El reconocimiento del derecho humano a la seguridad social como un derecho humano individual, autónomo y con características exigibles inmediatas, lo que garantiza su justiciabilidad. ${ }^{12}$

\section{Derecho internacional de la seguridad social en Europa}

\section{Aspectos generales de la zona geográfica en relación con la seguridad social}

El continente europeo destaca por varias razones en el ámbito de la seguridad social. Primero, porque la figura jurídica del seguro social ha sido legada al mundo desde Alemania, cuyo desarrollo ha permitido que sus habitantes gocen de los beneficios espléndidos que ofrecen sus catálogos de prestaciones, los cuales son de los más amplios en el mundo entero, sin omitir el excelente nivel cualitativo; segundo, también destaca por su desarrollo económico, que lo coloca en el mundo contemporáneo como una potencia, lo cual se ve reflejado en los beneficios de seguridad social; tercero, por la base para la construcción de la universalidad de la seguridad social a partir del Plan Beveridge; y por último, cuarto, por su asombrosa integración regional, que se ha desarrollado desde que se firmó en 1951 en París el Tratado Constitutivo de la Comunidad Europea del Carbón y del Acero (CECA), hasta consolidarse como la Unión Europea que conocemos ahora y su correlativa armonización y coexistencia única en materia de seguridad social.

La seguridad social en Europa es un tema que se encuentra ligado a su desarro-

9. Sentencia del caso Cinco pensionistas con Perú, Corte Interamericana de Derechos Humanos, 28 de febrero de 2003, disponible en https://bit.ly/3I4gT 78 .

10. Sentencia del caso Acevedo Buendía y otros con Perú, Corte Interamericana de Derechos Humanos, 1 julio de 2009, disponible en https://bit.ly/3rkxlKi. Sentencia del caso Poblete Vilches y otros con Chile, Corte Interamericana de Derechos Humanos, 8 marzo de 2018, disponible en https://bit.ly/3rhuoua.

11. Sentencia del caso Trabajadores cesados del Congreso (Aguado Alfaro y otros) con Perú, Corte Interamericana de Derechos Humanos, 24 de noviembre de 2006, disponible en https://bit.ly/3rd6T5m.

12. Sentencia del caso Muelle Flores con Perú, Corte Interamericana de Derechos Humanos, 6 de marzo de 2019, disponible en https://bit.ly/3p4gqZW. 
llo histórico e influenciado por sus organismos internacionales regionales, los más importantes son: el Consejo de Europa, la Unión Europea y la Asociación Europea de Libre Cambio y aunque existen algunos otros, como la Organización para la Seguridad y la Cooperación en Europa, que tienen líneas directas de trabajo con temas de migración y derechos humanos, no se consideran para este artículo porque no regulan aspectos directos de la seguridad social.

En especial juega un papel importante la supranacionalidad característica de la globalización, ya que la Unión Europea coordina los regímenes de seguridad social de cada uno de sus países. Esto significa que la asistencia sanitaria, las pensiones, los beneficios por desempleo, las prestaciones familiares y otras prestaciones de la seguridad social están sujetas a la reglamentación no solo nacional, sino también europea.

Sin embargo, la supranacionalidad se encuentra desde hace más de una década bajo la presión de dos lados: desde el exterior por la creciente importancia de las instituciones internacionales y supranacionales, y desde el interior por un posible renacimiento de la regulación interna (Becker, 2012: 23) y se puede agregar que la presión aumenta cuando se habla de seguridad social desde el enfoque de la migración, ya que al ser Europa un gran Estado receptor, se debate entre los derechos que la Unión Europea reconoce a los migrantes y los beneficios que ellos necesitan.

La supranacionalidad es también una singularidad de la regulación de la seguridad social en Europa que ha servido de modelo para la concepción del Acuerdo de seguridad social de la Comunidad del Caribe; el Acuerdo multilateral de seguridad social del Mercado Común del Sur y el Convenio general sobre seguridad social adoptado por la Comunidad Económica de los Estados de África Occidental (Cedeao).

De forma tal que, el derecho internacional de la seguridad social europeo no se compone de una legislación uniforme en materia de los seguros sociales, común a todos los países miembros. Por el contrario, existen convenios y tratados internacionales, donde se incluyen lineamientos básicos del derecho a la seguridad social para todo el territorio europeo. Además, los reglamentos de la Unión Europea se ocupan no solo de armonizar los regímenes de seguridad social, sino de que estos no sean un obstáculo a la libre circulación.

No obstante, en Europa siguen esforzándose por dar protección de seguridad social a los migrantes, por lo que los Estados se encuentran ante la siguiente realidad:

- Los miembros de la Unión Europea tienen la obligación de dar el mismo trato a los nacionales de los demás Estados comunitarios;

- el trato regulado a los ciudadanos de países que cuentan con convenios con la Unión Europea y

- un trato humanitario a los migrantes de países sin relación específica bilateral.

Desde esta perspectiva, el mayor problema sigue siendo los migrantes irregulares. 
Organismos regionales que expiden normas y directrices de seguridad social

Los principales organismos regionales que incluyen normativa de seguridad social en Europa son:

- Consejo Europeo.

- Unión Europea.

- Asociación Europea de Libre Cambio.

- Sistema Europeo Común de Asilo (SECA).

- Comité Europeo de Derechos Sociales.

- Comité Económico y Social Europeo (CESE).

Principales instrumentos internacionales regionales en materia de seguridad social

Dentro del derecho internacional de la seguridad social europeo sobresale como instrumento regional no vinculante la Carta Comunitaria de los Derechos Sociales Fundamentales de 1989. Por lo que respecta a los instrumentos vinculantes se establecen los siguientes:

- Carta social europea.

- Código europeo de la seguridad Social de 1964 y revisado en 1990.

- Carta de los derechos fundamentales de la Unión Europea de 2000 y 2007.

- Acuerdos y protocolos del Consejo de Europa sobre prestaciones específicas de seguridad social como: i) Acuerdo provisional europeo relativo a los regímenes de seguridad social sobre vejez, invalidez y supervivientes del 11 de diciembre de 1953, vigente desde el 1 de julio de 1954; ii) Protocolo del acuerdo provisional europeo relativo a los regímenes de seguridad social sobre vejez, invalidez y supervivientes del 11 de diciembre de 1953, vigente desde el 1 de octubre de 1954; iii) Convenio europeo de asistencia social y médica del 11 de diciembre de 1953, vigente desde el 1 de julio de 1954; iv) Convenio europeo sobre protección social de los agricultores del 6 de junio de 1974, vigente desde el 7 de junio de 1977

- Reglamentos de coordinación de los sistemas de seguridad social en la Unión Europea.

- Sistema de intercambio electrónico de información sobre seguridad social (EESSI). 
En ese mismo sentido, se puede afirmar que la Unión Europea es el mejor ejemplo de regionalización de la seguridad social y que, como se puede comprobar, la negociación política para la integración económica fue la base para una integración comercial, que posteriormente se extendió a la conformación de un espacio común laboral y ciudadano. Cabe resaltar que sin el derecho internacional de la seguridad social y el derecho internacional del trabajo no hubiera sido posible lograr el nivel de desarrollo que tiene la unión.

\section{Justicia regional del derecho humano a la seguridad social}

Se puede señalar que el Parlamento y los tribunales de justicia comunes han cumplido una función relevante en el proceso de integración y de la garantía del derecho humano a la seguridad social para todos los europeos, a través de una gran cantidad de resoluciones sobre el derecho humano a la seguridad social.

Desde esa perspectiva, destaca la función de dos tribunales para salvaguardar ese derecho contribuyendo a una verdadera integración. El primero es el Tribunal Europeo de Derechos Humanos, que es el órgano judicial permanente que garantiza a todos los europeos los derechos consagrados en el Convenio Europeo de Derechos Humanos. El segundo es el Tribunal de Justicia de la Unión Europea, cuya principal función es garantizar que su legislación se interprete y aplique de la misma manera en cada uno de los países miembros y garantizar que estos y las instituciones europeas cumplan la legislación. ${ }^{13}$

A diferencia de la Corte Interamericana de Derechos Humanos, estos tribunales tienen la facultad de exigir, con base en las normas vigentes de la Unión Europea la protección de seguridad social a los ciudadanos de un país en otro, por tratarse de una comunidad política de derecho que propicia la integración y gobernanza en común de los Estados y sus ciudadanos.

\section{Derecho internacional de la seguridad social en África}

Aspectos generales de la zona geográfica en relación con la seguridad social

África es un continente que a lo largo de la historia ha pasado por una serie de sucesos que marcaron su desarrollo en aspectos económicos, políticos, sociales y culturales. La colonización por parte de Inglaterra, Francia, Italia, España, Alemania y Bélgica trajo consigo la implementación de ideologías correspondientes a la cultura y tradiciones del continente europeo, en la que claramente se marcó una separación entre los nativos africanos y los europeos.

13. «Tribunal de Justicia de la Unión Europea (TJUE)», web oficial de la Unión Europea, disponible en https://bit.ly/302CvZA. 
En ese tenor, la adopción de instrumentos internacionales en materia de seguridad social tuvo un gran atraso en ese continente, sobre todo porque no fue hasta finales de los años cincuenta del siglo pasado - cuando comenzó la independencia de dichas colonias para convertirse en países soberanos-, que los países comenzaron a organizarse de manera autónoma.

África es una región en la que existe una gran pluralidad de costumbres, gobiernos, religiones y formas de vida que hacen único a cada Estado y dificultan la integración regional y más aún la coordinación o estandarización de prestaciones de seguridad social. No obstante, existen organismos que han buscado la integración regional para la unificación de algunos aspectos — sobre todo económicos, de salud, paz, empleo y de seguridad pública y social - con el objetivo de elevar la calidad de vida de los ciudadanos.

Hablando de integración regional, se advierte en este continente una fragmentación en al menos cuatro partes.

Los países árabes del norte del Sahara integran la región conocida como Medio Oriente y es hacia allí que dirigen sus expectativas políticas, culturales y religiosas antes que hacia el resto del continente africano. En el Oriente, guerras y colapsos estatales que alcanzan su cúspide en el Cuerno de África tornan irreal cualquier discurso sobre integración regional: parafraseando a Robert Jackson (1990), cuasi Estados no dan lugar a una cuasi integración. Las áreas de África occidental y austral, en cambio, han creado organizaciones regionales que perduran en el tiempo, aunque su desempeño es asimétrico e irregular (Malamud, 2011: 237-238).

\section{Organismos regionales que expiden normas y directrices de seguridad social}

A nivel regional, es el continente con mayor número de organismos que agrupan a la mayoría de los países africanos. En ese tenor, son más de 200 organismos regionales que se organizan y participan por sectores de cooperación y todos ellos tienen como finalidad el bienestar de sus habitantes a través de varias directrices, como el crecimiento económico, la agricultura y el combate a la desnutrición.

Algunos organismos regionales que incluyen normativa de seguridad social en África son:

- Unión Africana.

- Comunidad Económica de los Estados de África Occidental.

- Comunidad para el Desarrollo de África Meridional.

- Conferencia Interafricana de Seguridad Social.

- Autoridad Intergubernamental para el Desarrollo. 
- Mercado Común del África Oriental y Meridional.

- Comunidad de África Oriental.

También se encuentra que, en esta región, los instrumentos jurídicos más importantes en materia de migración son cinco:

- Convención de la Organización de la Unión Africana (1969) (Convention governing the specific aspects of refugee problems in Africa).

- Carta africana de derechos humanos y de los pueblos (1981), con sus respectivos protocolos relacionados con la seguridad social: 1) Protocolo de la Carta africana de derechos humanos y de los pueblos sobre los derechos de las mujeres en África (2003); 2) Protocolo de la Carta africana de derechos humanos y de los pueblos sobre los derechos de las personas mayores (2016).

- Acuerdo de asociación de África, el Caribe y el Pacífico y la Comunidad Europea y sus Estados miembros (2000) (The Cotonou Agreement).

- Declaración conjunta África y Unión Europea sobre migración y desarrollo (2006).

- Convención de la Unión Africana para la protección y la asistencia de los desplazados internos en África (2009).

Principales instrumentos internacionales regionales en materia de seguridad social

El derecho internacional de la seguridad social africano se nutre de los siguientes instrumentos internacionales: ${ }^{14}$

Instrumentos vinculantes:

- Convención de la Organización de la Unión Africana.

- Acuerdo de asociación de África, el Caribe y el Pacífico y la Comunidad Europea y sus Estados miembros.

- Protocolo sobre libre circulación de personas, trabajadores, servicios, el derecho de establecimiento y residencia del mercado común del África Oriental y Meridional, Comesa (Protocol on free movement of persons, labour, services, the right of establishment and residence).

- Carta de los derechos sociales fundamentales de la Comunidad para el De-

14. Algunos instrumentos internacionales se repiten con los que regulan la migración, en función de que contemplan ambos derechos. 
sarrollo del África Austral, SADC (Charter of fundamental social rights in $\mathrm{SADC})$ (2003).

- Convenio de la conferencia interafricana sobre seguridad social (Convention multilatérale de sécurité sociale).

- Código de seguridad social de la Comunidad para el Desarrollo de África Meridional, CDAM (Code on social security in the SADC).

- Convención general de seguridad social de la Comunidad Económica de los Estados de África Occidental, Cedeao (General convention on social security, Ecowas).

En tanto, los instrumentos no vinculantes más importantes son los siguientes:

- Carta africana de derechos humanos y de los pueblos (African charter on human and people's rights).

- Declaración conjunta África-Unión Europea sobre migración y desarrollo (Joint Africa-European Union declaration on migration and development) (2006).

- Convención de la Unión Africana para la protección y la asistencia de los desplazados internos en África (African Union convention for the protection and assistance of internally displaced persons in Africa) (2009).

Estos organismos regionales, que integran una comunidad estrecha entre los Estados miembros, dan pauta para el cumplimiento de los instrumentos vinculantes y no vinculantes que conforman el derecho internacional de la seguridad social africano.

\section{Justicia regional del derecho humano a la seguridad social}

El proceso de integración regional, en un continente tan extenso y con aspectos socioeconómicos diversos como el africano, motiva un intento por superar conjuntamente los problemas comunes y progresar económicamente y socialmente. ${ }^{15}$ Uno de los mecanismos para lograr ese cometido es la integración de normas que contemplen derechos sociales en beneficio de las sociedades, por ende, la integración regional en África es importante y guarda una estrecha relación con el derecho internacional de la seguridad social pues a través de esta disciplina se genera protección social a las personas mediante las prestaciones que contemplan los marcos internacionales y nacionales de los Estados que forman parte de una región específica del continente.

En ese contexto, uno de los organismos para la protección de los derechos huma-

15. «Integración regional», Ministerio de Asuntos Exteriores, Unión Europea y Cooperación, Gobierno de España, 2020, disponible en https://bit.ly/3 $\mathrm{C}_{3} \mathrm{kgXz}$. 
nos en el continente africano es la importante Corte Africana para el Pueblo y Derechos Humanos. Esta corte es uno de los tres principales órganos pertenecientes al sistema africano de derechos humanos que engloba tratados, principios e instituciones independientes de la Unión Africana. Tiene fundamento en el artículo primero del Protocolo de la Carta Africana de Derechos Humanos y de los Pueblos que entró en vigor en 2004, pero oficialmente la corte comenzó sus operaciones en noviembre de 2006.

La corte tiene dos funciones primordiales: una consultiva y una contenciosa. ${ }^{16}$ Cuenta con el propósito y jurisdicción para interpretar y aplicar la Carta Africana sobre Derechos Humanos y de los Pueblos, el mismo protocolo y cualquier otro instrumento ratificado por los Estados pertenecientes que garanticen la protección de derechos humanos y de los pueblos en África; tiene sede en Arusha, República Unida de Tanzania.

Sobre las controversias en materia de seguridad social, de la página electrónica de la propia corte se desprende que de los asuntos concluidos o finalizados en ninguno de ellos la parte reclamante consideró vulnerados sus derechos de seguridad social, por lo que a la fecha no existe pronunciamiento del tribunal con respecto a este tema.

Sin embargo, la Corte Africana tiene la posibilidad de contribuir a la regionalización del derecho internacional de la seguridad social de los Estados miembros a través de sus decisiones jurisdiccionales, ya sean originadas por un procedimiento contencioso o en su naturaleza consultativa, debido a que mediante estas sentencias unifica determinados criterios que permiten a los países que se someten a su jurisdicción homogenizar sus marcos normativos nacionales, con base en lo establecido por este órgano internacional.

De lo anterior, como el órgano internacional jurisdiccional máximo del continente, la corte da pauta para que exista una regionalización en determinadas zonas geográficas de África para estrechar normas jurídicas, aplicables de una manera concreta en los países parte de la región.

\section{Derecho internacional de la seguridad social en Asia}

Aspectos generales de la zona geográfica en relación con la seguridad social

Asia es un continente con grandes contrastes económicos, sociales y culturales. La reducción acelerada en sus índices de pobreza parte de su población ${ }^{17}$ ha repercutido

16. «The African Court in Brief», African Court on Human and Peoples' Rights, disponible en https:// bit.ly/3n1X8EJ.

17. Por ejemplo, China redujo el porcentaje de población que vive con menos de dos dólares americanos de $84,9 \%$ en 1990 a $26,8 \%$ en 2010 ; Indonesia pasó en el mismo período de $84,6 \%$ a $46,1 \%$ y Tailandia de 37,1\% a 4,1\% (Linnarz, 2014: 29). 
también en el desarrollo de sus sistemas de seguridad social y en la construcción del derecho internacional de la seguridad social regional. De un lado, está integrado por países que trabajan por consolidar sus sistemas de seguridad social — sobre todo los que son miembros de la Organización para la Cooperación y el Desarrollo Económicos (OCDE) -; mientras que del otro lado hay algunos cuyo desafío es crear la infraestructura elemental para brindar protección básica que dé cobertura a una importante parte de la población. Población que trabaja en el sector informal y que lucha para que le alcance el dinero hasta fin de mes, en una época en la que los cambios económicos mundiales y los cambios demográficos mundiales contribuyen a aumentar las incertidumbres políticas y de sistema político (Walker y Pellissery, 2008: 84).

En ese contexto, la integración regional dentro de los países que conforman el continente asiático ha contribuido al establecimiento de normas homologadas en materia de seguridad social.

\section{Organismos regionales que expiden normas y directrices de seguridad social}

Son pocos los organismos que se ocupan de la integración regional en Asia y en materia específica de seguridad social solo sobresale la Asociación de Seguridad Social de la Asean $^{18}$ (ASSA), que a su vez forma parte de un organismo regional. Este bloque formado por 10 países, geográficamente se localiza entre China, la India y el océano Pacífico y el Índico.

Los principales organismos regionales que incluyen normativa de seguridad social en Asia y Oceanía son:

- Asociación de Seguridad Social de la Asean (Asean Social Security Association, ASSA).

- Asociación de Naciones del Sudeste Asiático (Association of Southeast Asian Nations, ASEN).

- Consejo de Cooperación para los Estados Árabes del Golfo (The Cooperation Council For The Arab States Of Gulf, GCC).

- Asociación del Sur de Asia para la Cooperación Regional (South Asian Association For Regional Cooperation, SAARC).

- Cooperación Económica Asia-Pacífico (Asia Pacific Economic Cooperation, APEC).

18. Asociación de Naciones del Sureste Asiático, Asean (por sus siglas en inglés). 


\section{Principales instrumentos internacionales} regionales en materia de seguridad social

Si bien el objetivo original de la Asociación de Naciones del Sureste Asiático (Asean) era acelerar el crecimiento económico y fomentar la paz y seguridad regionales, ha ido aumentando su alcance y de esa forma, hoy en día, incluyen normas también de seguridad social, que contribuyen al desarrollo del derecho internacional de la seguridad social regional.

El derecho internacional de la seguridad social en Asia y Oceanía se nutre de los siguientes instrumentos no vinculantes:

- Consenso de la Asean sobre la protección y promoción de los derechos de los migrantes.

- Declaración de la Asean sobre el fortalecimiento de la protección social.

- Marco regional y plan de acción para aplicar la declaración de la Asean sobre el fortalecimiento de la protección social.

Los instrumentos vinculantes son:

- Declaración de Cebú para la protección y promoción de los derechos de los trabajadores migrantes.

- Ley unificada de extensión de protección de seguros para ciudadanos del Consejo de Cooperación del Golfo fuera de sus países.

En ese contexto, la integración regional dentro del continente asiático presenta particularidades diversas a las americanas o europeas. Por ejemplo, no hay una tendencia a la expedición de normas jurídicas conjuntas, ni a la institucionalización regional, ni siquiera hay un tribunal internacional regional y desde la década de los noventa del siglo pasado, la Asean way establece cuatro principios que rigen el cumplimiento de sus objetivos: la no intervención, la diplomacia blanda, la exclusión del uso de la fuerza (a diferencia de la ONU que puede intervenir bélicamente) y la toma de decisiones por consenso (cada miembro tiene la misma posición que los tomadores de decisiones).

Por lo tanto, aunque los Estados integran una región y comparten determinadas similitudes, no hay una marcada tendencia a la integración regional en materia de seguridad social. En los últimos años, se mantiene un desarrollo local diverso entre un país y otro. Por ejemplo, mientas que China se develó como el país con mayor avance en cobertura de seguridad social a sus habitantes, recibiendo el premio de la Asociación Internacional de la Seguridad Social (en inglés, AISS); ${ }^{19}$ Japón mantiene sus altos

19. Premio buenas prácticas de la AISS, Asia y el Pacífico, 2018. 
estándares de seguridad social y países como Kazajistán y Uzbekistán, pertenecientes a Asia central, presentan un gran rezago (OIT, 2020).

\section{Justicia regional del derecho humano a la seguridad social}

En la región asiática no existe un órgano jurisdiccional que aplique normas regionales en materia del derecho humano a la seguridad social, aunque sí existe un organismo no gubernamental que promueve la protección de los derechos humanos. Se trata de la Comisión Asiática de Derechos Humanos, fundada en 1984 por un grupo de activistas especialistas de derechos humanos; es un organismo independiente, que busca promover mayor conciencia y respeto a los derechos humanos en la región asiática, además de movilizar a la opinión pública asiática e internacional para obtener socorro y reparación para las víctimas de violaciones de derechos humanos; no obstante, poco contribuye la regionalización del derecho internacional de la seguridad social asiático.

Ciertamente la complejidad del continente asiático, derivado del choque de culturas y aspectos históricos entre los países que lo conforman, trae como consecuencia la difícil integración de regiones entre Estados; sin embargo, comisiones como la mencionada, dan pauta a la apertura al diálogo vislumbrando el reconocimiento del derecho humano a la seguridad social en el continente asiático.

\section{Reflexiones a manera de conclusión}

Con base en el análisis que se presenta en este artículo, se concluye que el derecho internacional de la seguridad social es una vía para atender la problemática de otorgar prestaciones de seguridad social a un trabajador en el extranjero.

Dentro de la concreción del derecho humano a la seguridad social los organismos internacionales de seguridad social juegan un gran papel, ya sea mediante el establecimiento de estándares internacionales - como los convenios de la OIT-o inclusive formulando acuerdos vinculantes entre sus miembros, como el Convenio Multilateral Iberoamericano de Seguridad Social.

El enfoque meramente bilateral de los convenios de seguridad social comienza a quedar obsoleto ante la complejidad del actual fenómeno migratorio, que se aleja de conceptos clásicos tales como estabilidad e integración en el nuevo país de empleo y de residencia, ocasionados por los diversos tipos de migración: migraciones circulares, sucesivas múltiples, desplazamientos temporales de trabajadores, migraciones irregulares, etcétera.

Para formalizar el derecho internacional de la seguridad social, de un lado se pueden establecer acuerdos bilaterales con los países vecinos, para garantizar la protección de seguridad social de los ciudadanos de un país en el territorio vecino, pero 
son mucho más efectivos los acuerdos multilaterales, que permiten la negociación por bloque. Es más conveniente negociar en bloque que de forma individual, de país a país.

En ese sentido, los procesos de integración regional de cada continente -iniciados por la unión geográfica para atender necesidades comunes, eminentemente económicas-, al avanzar en su desarrollo y pasar de una etapa de integración a otra, comienzan a incluir otros temas como el de la seguridad social.

Los niveles de institucionalización de los bloques regionales son heterogéneos y solo la Unión Europea alcanza las cuatro libertades garantizadas contractualmente para el comercio, el capital, los servicios y las personas. En las últimas décadas se nota una clara tendencia a la integración regional, sobre todo si se analiza (como en este artículo) desde la creación de organismos de derecho internacional de la seguridad social a la gran cantidad de instrumentos internacionales de derecho vinculante y derecho no vinculante que constituyen una de sus fuentes más importantes.

Una de las principales conclusiones de este artículo es que la integración regional impulsa el derecho humano a la seguridad social, a través de sus normas internacionales y de las resoluciones de sus órganos regionales de impartición de justicia. Pero, del análisis del derecho internacional de la seguridad social por continente $-\mathrm{y}$ tomando como base las cuatro etapas de la integración regional (zona de libre comercio, unión aduanera, mercado común y unión económica)-, se advierte que no es posible llegar a una completa regionalización, a una verdadera integración regional, sin la consolidación del derecho internacional de la seguridad social regional.

Si bien la regionalización incluye como parte de su proceso en la tercera y cuarta etapa (mercado común y unión económica) la conformación de normas de coordinación y la armonización u homologación de los derechos, no habrá una verdadera integración si no existe el andamiaje jurídico adecuado en materias de seguridad social, puesto que como derecho humano es indispensable que no esté limitado por las fronteras. El derecho humano a la seguridad social no es una maleta que se deja al cruzar la frontera.

El derecho internacional de la seguridad social constituye una de las mejores soluciones que se puede tener para otorgar prestaciones de seguridad social a los migrantes (aun aquellos con estatus migratorio irregular), pues responde a las necesidades humanas, la concreción de un derecho humano y fomenta el principio de reciprocidad internacional. Sus normas hacen realidad y solucionan la problemática de que los nacionales de un Estado reciban prestaciones de seguridad social, a través de diversos mecanismos, en otro Estado. 


\section{Referencias}

Balassa, Bela (1965). El desarrollo económico y la integración. Ciudad de México: Centro de Estudios Monetarios Latinoamericanos.

BeCKeR, Ulrich (2012). Die Sozialpolitik im Spannungsverhältnis von Nationalstaat und supranationalen Institutionen. Sozialer Fortschritt, 61 (5): 86-92. Disponible en https://bit.ly/3lubc8J.

CÁrdenas García, Jaime (2009). Introducción al estudio del derecho. Ciudad de México: Nostra.

Cepal, Comisión Económica para América Latina y el Caribe (2014). Integración regional: Hacia una estrategia de cadenas de valor inclusivas. Santiago: Cepal. Disponible en https://n9.cl/31c24.

FANJUL, Enrique (2021). ¿Qué es la globalización?. Madrid: Iberglobal Escuela de comercio. Disponible en https://bit.ly/3DmmG5a.

Felbermayr, Gabriel, Gerhard Illing, Jürgen Pfister, Stephan Klasen, Michael Jakob, Heinz-Jürgen Axt y Harold James (2015). «Globalisierung und regionale Integration: ÖkonomischeEntwicklungen, Perspektiven und Grenzen». ifo Schnelldienst, 68 (16): 3-30. Disponible en https://bit.ly/3mTNVy8.

GonzÁlez Carvallo, Diana Beatriz, Odette Ivonne Maldonado Bernal (2021). «Derecho a la seguridad social. Pensión por viudez en el concubinato». Cuadernos de Jurisprudencia, 5. Disponible en https://bit.ly/3bWwZAU.

Konkolewsky, Hans-Horst (2007). «La Asociación Internacional de la Seguridad Social y la seguridad y salud en el trabajo». Seguridad del Trabajo, 53 (209). Disponible en https://bit.ly/31vyUdK.

Malamud, Andrés (2011). «Conceptos, teorías y debates sobre la integración regional». Norteamérica, 6 (2): 219-249. Disponible en https://bit.ly/3ddAQtE.

MendizÁbal Bermúdez, Gabriela (2020). Derecho internacional de la seguridad social. Ciudad de México: Porrúa.

MendizÁbal Bermúdez, Gabriela y Óscar Javier Apáez Pineda (2020). «Análisis del derecho humano de la seguridad social desde el convenio bilateral vigente entre México y España». e-Revista Internacional de la Protección Social, 5 (1): 243-258. Disponible en https://bit.ly/2ZTHKS4.

Montoya Melgar, Alfredo (1964). «El derecho internacional de la seguridad social». Revista de Política Social, 61: 381-399. Disponible en https://bit.ly/30gAvga.

OIT, Organización Internacional del Trabajo (2020). «Protección social universal para la dignidad humana, la justicia social y el desarrollo sostenible». Disponible en https://bit.ly/2ZRTioS.

Pampillo Baliño, Juan Pablo (2019). Nuevas reflexiones sobre la integración jurídica latinoamericana. Lima: Rimay. 
WALKer, Robert, Sony Pellissery (2008). «Nuevos y viejos gigantes: promoción de la seguridad social y crecimiento económico en la Región de Asia y el Pacífico». Revista Internacional de Seguridad Social, 61 (2): 93-118. Disponible en https://bit. ly/3DjwZG7.

\section{Sobre la autora}

Gabriela Mendizábal Bermúdez es licenciada en derecho por la Universidad Nacional Autónoma de México (UNAM), maestra y doctora en derecho por la Universidad de Viena, Austria. Actualmente es profesora investigadora de la Facultad de Derecho y Ciencias Sociales de la Universidad Autónoma del Estado de Morelos (UAEM), miembro del Sistema Nacional de Investigadores del Conacyt (nivel 2) en México y corresponsal oficial de México en el Instituto Max Planck de Derecho Social y Política Social de Alemania. Su correo electrónico es mgabriela@uaem.mx. (D) https://orcid.org/00oo-0003-3681-4025. 
La Revista Chilena de Derecho del Trabajo y de la Seguridad Social es una publicación semestral del Departamento de Derecho del Trabajo y de la Seguridad Social de la Facultad de Derecho de la Universidad de Chile, y que tiene por objetivo el análisis dogmático y científico de las instituciones jurídico-laborales y de seguridad social tanto nacionales como del derecho comparado y sus principales efectos en las sociedades en las que rigen.

\author{
DIRECTOR \\ Luis Lizama Portal \\ EDITOR \\ Claudio Palavecino Cáceres \\ SECRETARIO DE REDACCIÓN \\ Eduardo Yañez Monje \\ SITIO WEB \\ revistatrabajo.uchile.cl \\ CORREO ELECTRÓNICO \\ pyanez@derecho.uchile.cl \\ LICENCIA DE ESTE ARTÍCULO \\ Creative Commons Atribución Compartir Igual 4.o Internacional
}

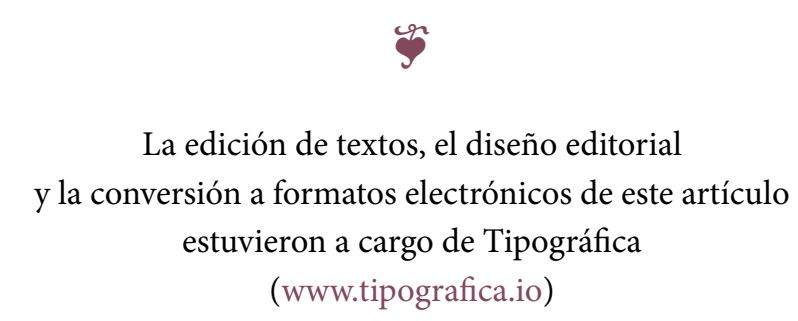

